\title{
Dental İmplant Abutmenti-Rezin Siman Bağlanma Dayanımı Üzerine Farklı Yüzey Pürüzlendirme İșlemlerinin Etkisinin İncelenmesi
}

\author{
Investigation Of The Effect Of Different Surface Processes On The Bonding \\ Strength of Dental Implant Abutment - Resin Cement
}

\author{
Hasan GÜNGÖR ${ }^{* 1}$ (D) \\ hasangungor06@icloud.com
}

Zeynep YEŞiL DUYMUŞ² (D)

zyesilz@hotmail.com

\begin{abstract}
ÖZ
Amaç: Bu çalışmanın amacı, farklı yüzey pürüzlendirme işlemleri uygulanan titanyum alaşımı dental implant abutment materyaline, iki farklı rezin simanın bağlanma dayanımının karşılaștırılmasıdır.

Gereç ve Yöntemler: Çalışmada, her grupta 20 adet olacak şekilde toplam 120 adet örnek hazırlandı. Örnekler; elmas porselen frez ile pürüzlendirme, kumlama, silika kaplama, lazer ile pürüzlendirme, fosforik asit ile pürüzlendirme ve kontrol grubu olmak üzere altı farklı gruba ayrıldı. Yüzey pürüzlendirme ișlemleri yapıldıktan sonra, örneklerin yüzeylerinin topografik incelemesini yapabilmek için taramalı elektron mikroskobu (SEM) görüntüleri alındı. Yüzey ișlemi uygulanan ve uygulanmayan her bir gruptaki örneklerin yarısına (10 örnek) Alloy Primer uygulandıktan sonra Panavia F rezin siman, diğer örneklere ise herhangi bir metal primer uygulanmadan Multilink Sprint rezin siman uygulandı. 37 oC' de su banyosunda 24 saat süre ile bekletilen örnekler, universal test makinesinde kesme (shear) testine tabi tutuldu.

Bulgular: Çalışmada, en yüksek bağlanma dayanımı değerleri Panavia F rezin siman uygulanan elmas frez ile pürüzlendirmeye ilave olarak Co-Jet yöntemi ile pürüzlendirme yapılan grupta elde edilirken, en düşük bağlanma dayanımı değerleri ise Multilink Sprint rezin siman uygulanan yüzey işlemi yapılmayan grupta tespit edildi.

Sonuç: Lazer ve asit ile yapılan pürüzlendirmenin titanyum örneklerin yüzey yapısını değiştirmede etkili olmadığı kanaatine varıldı. Kırılmaların tamamının adeziv başarısızlık şeklinde olması, rezin siman ve Ti-6Al-4V örnekler arasında gerçek anlamda kimyasal bir bağlantının sağlanamadığına işaret etmektedir.
\end{abstract}

Anahtar Kelimeler: Dental Abutment, Rezin Siman, Bağlanma

$\begin{array}{lll}\text { Geliş: 27.03.2021 Kabul: 08.07.2021 } & \text { Yayın: 25.08.2021 }\end{array}$

\begin{abstract}
Aim: The aim of this study was to compare the bonding strength of 2 different resin cement to the dental implant abutment material from titanium alloy, which were applied different surface roughing processes.

Material and Methods: In our study, a total of 120 samples were studied, with 20 samples in each group. The samples were divided into 6 different groups: roughing with diamond porcelain milling, sandblasting, silica coating, laser roughening, phosphoric acid roughing and control group, respectively. After surface roughing operations, scanning electron microscope images were taken to perform topographic examination of the surfaces of the samples. After applying Alloy Primer to half of the samples in each group where surface treatment is applied and not applied, Panavia F resin siman was applied and Multilink Sprint resin siman was applied to other samples without applying any metal primers. Samples kept in a water bath at $37 \mathrm{oC}$ for 24 hours were subjected to shear test in a universal test machine.

Results: In the study, the group roughened with the Co-Jet method in addition to roughening the highest binding strength with the diamond mill applied with Panavia F resin siman, while the lowest binding strength values were the Multilink Sprint resin siman applied surface treatment group.

Conclusion: It has been concluded that the roughening with laser and acid is not effective in changing the surface structure of titanium samples. The fact that all breaks are in the form of adeziv failure indicates that a truly chemical link between resin siman and Ti-6Al-4V samples cannot be achieved.
\end{abstract}

Keywords: Dental abutment, Resin Cement, Bonding

Received: 27.03 .2021

Accepted: 08.07.2021

Published: 25.08.2021

Atıf / Citation: Güngör H, Duymuş ZY. Dental implant abutmenti-rezin siman bağlanma dayanımı üzerine farklı yüzey pürüzlendirme işlemlerinin etkisinin incelenmesi. NEU Dent J. 2021;2:49-55.

* Sorumlu Yazar / Corresponding Author
1. Necmettin Erbakan Üniversitesi, Diş Hekimliği Fakültesi, Ortodonti AD, Konya, Türkiye
2. Serbest Ortodontist, Bandırma/Balıkesir, Türkiye




\section{Gíriş}

Dental implant abutmenti; implantın, sabit veya hareketli protezin desteklenmesine ve tutuculuğuna hizmet eden parçası için kullanılan terimdir. İmplant destekli protezlerde kullanılan abutment çeşitleri tedavi planlamasına ve yapılacak protezin tipine göre değișiklik göstermektedir. Üretici firmalar tarafından çeşitli amaçlara hizmet eden çok sayıda abutment bulunmaktadır. İmplant abutmentleri günümüzde, siman bağlantıll, vida tutuculu ve ataşman tutuculu olmak üzere üç gruba ayrılmıştır. ${ }^{1,2}$ Siman bağlantılı implant abutmentleri diğer tiplerden daha fazla kullanılmaktadırlar. ${ }^{3,4}$ İmplantın üst bölümü dişetinden $3 \mathrm{~mm}$ den daha az derinlikte ise simante tip abutment tercih edilebilir. ${ }^{5}$

Dental implant abutmenti ile farklı simanların bağlanma dayanımının incelendiği araştırmalarda, en yüksek bağlanma dayanımı rezin simanlarla elde edildiğinden, ${ }^{6-8}$ dental implant abutmentlerinin simantasyon işleminde rezin simanların tercih edilmesi gerektiği ifade edilmektedir. ${ }^{6,9}$

Abutmentler ile simanların adezyonunu artırmak amacıyla farklı yüzey pürüzlendirme yöntemleri kullanılabilmektedir. ${ }^{10-12}$ Metal alaşımları ile rezin siman bağlanma mekanizması; makro-mekanik (pozitif), mikro-mekanik (negatif) ve kimyasal adezyon + mikro-mekanik olmak üzere üç ana sistemle oluşmaktadır. ${ }^{13}$

Bu çalıșma, dental implant abutmenti yapımında kullanılan materyaller arasında ilk sırayı alan titanyum alaşım (Ti-6Al-4V) örneklere uygulanan farklı yüzey pürüzlendirme işlemlerinin, iki farklı rezin simanın bağlanma dayanımına etkisini karşılaştırmalı olarak incelemek amacıyla yapılmıştır.

Çalışmanın sıfır hipotezi titanyum alaşım örneklere uygulanan yüzey pürüzlendirme işlemlerinin rezin simanların bağlanma dayanımını arttıracağı yönündedir.

\section{GEREÇ VE YÖNTEMLER}

Çalışmada, titanyum alaşımından $12 \mathrm{~mm}$ çapında, 10 mm kalınlığında prefabrik silindir bloklar (Hint-Els, Griesheim, Germany) kullanıldı. Örnekler, Isomet hassas kesme cihazında, (ISOMET: Low Speed Saw, Buehler lake Bluff, IL USA) elmas disk (Diamond Wafering Blade Series 15 HC Diamond No. 11-4244, IL USA) kullanılarak sulu soğutma sistemiyle kesilerek hazırlandı (Şekil 1). Hazırlanan toplam 120 adet örnek, her grupta 20 adet örnek olacak şekilde altı gruba ayrıldı. Bu altı gruba aşağıda belirtilen yüzey pürüzlendirme işlemleri uygulandı:
Şekil 1: Çalıșmada kullanılan örnekler

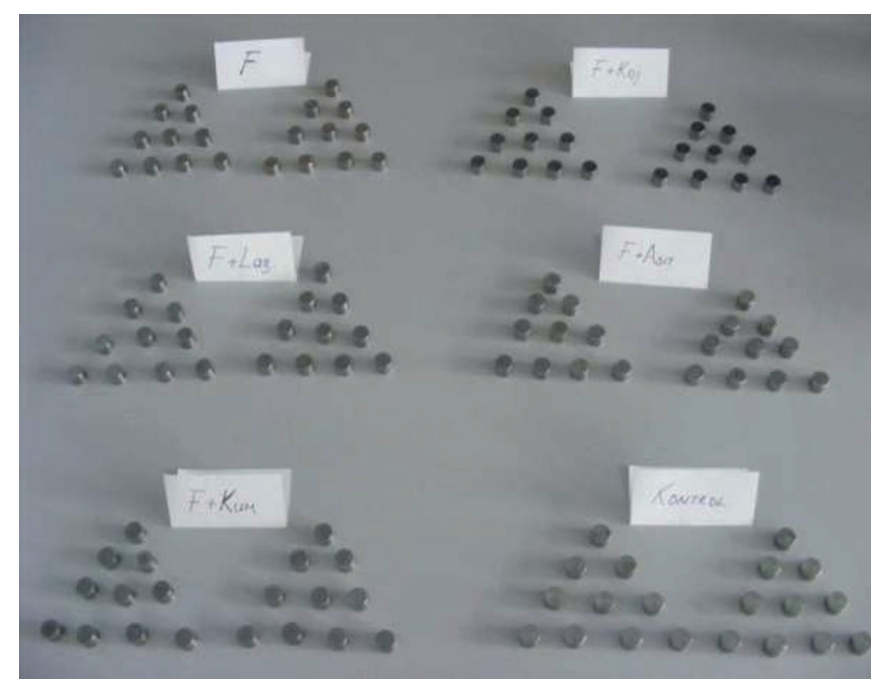

1. Grup: Aynı araştırıcı tarafından 20 adet örnek orta grenli aynı tipte elmas porselen bitirme frezi (Diamond mounted poin, Dentant, Malesia) ile 15000 devir hızda dönen mikromotor piyasemeni kullanılarak çeșitli yönlerde pürüzlendirildi.

2. Grup: Bu gruptaki örnekler frez ile pürüzlendikten sonra ince kalem uçlu kumlama cihazıyla (Macro cab, Danville Engineering, Inc. USA) partikül büyüklügü $50 \mu$ m olan $\mathrm{Al}_{2} \mathrm{O}_{3}$ kum (DynaFlex, St.Loius, USA) ile 2.5 atmosfer hava basıncı altında yaklaşı $10 \mathrm{~mm}$ mesafeden 60 saniye süreyle kumlandı.

3. Grup: Frez ile pürüzlendirilen 20 adet titanyum alaşım örneğin yüzeyi, Co-Jet sistemi (3M ESPE AG; Germany) kullanılarak SiO içeren $30 \mu m^{\prime}$ lik $\mathrm{Al}_{2} \mathrm{O}_{3}$ kumu ile $90^{\circ}$ açıyla, 15 saniye boyunca kumlanarak silika kaplandı.

4. Grup: Frez ile pürüzlendirilen 20 adet titanyum örnek daha sonra Er:YAG lazer cihaziyla (Doctor Smile Erbium \& Diode Laser, Lambda Scientifia, S.r.l, Vicenza, Italy) pürüzlendirildi.

5. Grup: Hazırlanan 20 adet titanyum alaşım örneğin yüzeyine frez ile pürüzlendirme işlemi yapıldıktan sonra 60 saniye süreyle \% 37' lik fosforik asit (Scotcbond, 3M ESPE; Germany) uygulandı ve daha sonra hava ve su spreyi altında ön temizleme işlemi yapıldı.

6. Grup: Bu gruptaki 20 adet örnek hiçbir yüzey hazırlığına tabi tutulmamış ve Isomet hassas kesme cihazından çıktığı şekilde yüzey işlemi yapılmayan grup olarak birakıldı.

Hazırlanan titanyum örneklere rezin simanların standart bir şekilde uygulanabilmesi için, iç boşluk çapı $5 \mathrm{~mm}$, kalınlığı $4 \mathrm{~mm}$ olan halka şeklinde teflon kalıplar kullanıldı (Şekil 2). Panavia F rezin siman (Panavia F, Kuraray Dental, Japan) ve Multilink Sprint rezin siman (Multilink Sprint, Ivoclar Vivadent) üretici firmanın önerileri doğrultusunda uygulandı. Bütün örneklerde siman uygulandıktan sonra halkanın 
üzerine selüloz bir bant kapatılıp örnek üzerine 400 gr. standart ağırlık tatbik edilerek, simanın kendiliğinde sertleșmesi için oda ısısında 10 dakika beklenildi.

Şekil 2: Simantasyonda kullanılan teflon halka

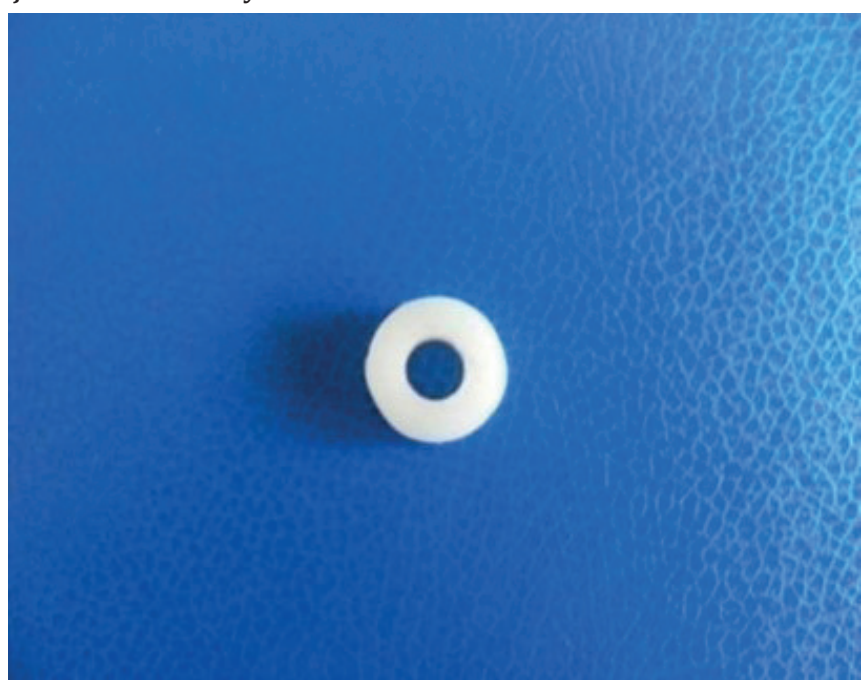

Örnekler, simantasyon sonrasında bağlanma dayanımı ölçülmeden önce içinde $37^{\circ} \stackrel{\circ}{C}$ de distile su bulunan su banyosunda (Grant Instruments, Cambridge, England) 24 saat süre ile bekletildi. Bağlanma dayanımı testi için Instron Universal test cihazı (Instron Corp, USA) kullanıldı. Ölçüm öncesinde örnek özel hazırlanan metal test düzeneğine yerleștirilerek, bu düzenek yardımıyla test cihazının bir ucuna sabitlendi. Ayrılmanın gerçekleștiği noktadaki kuvvet değeri Newton cinsinden kaydedildi. Elde edilen değerler 5 mm çapındaki yapıșma yüzeyinin alanı olan 12.5599 $\mathrm{mm}^{2}$ ye bölünerek MPa'a çevrildi.
Calıșmanın SEM analizleri taramalı elektron mikroskobu (JEOL/JSM, 5600 Tokyo, Japan) ile yapıldı. SEM analizi öncesi örnekler kurutulup alüminyum blok özerine yapıștırıcı bir bant yardımıyla sabitlendi. Sonrasında bir püskürtme cihazı yardımıyla örneklerin yüzeyi $200 \quad \mathrm{~A}^{\mathrm{o}}$ kalınlığında altın ile kaplanarak, 500 büyütmede yüzey görüntüleri alındı.

\section{İstatistiksel Değerlendirme:}

Elde edilen verilerin istatistiksel değerlendirmesi, SPSS 12.0 paket programında, iki yönlü (ANOVA) varyans analizi kullanılarak yapıldı. Ortalama ve standart sapmalar hesaplandı, çoklu karșılaștırmalar için Duncan testi kullanıldı.

\section{BULGULAR}

\section{Kesme (Shear) testi bulguları:}

Farklı yüzey işlemleri açısından iki farklı simanın bağlanma dayanımına ait ortalama ve standart sapma sonuçları Tablo 1'de gösterilmiștir. En yüksek bağlanma dayanımı değerleri Panavia F frez + Co-Jet grubunda (15.96 MPa) saptanmıștır. Bu grubu sırası ile Multilink S frez + Co-Jet (15.22 MPa), Panavia F frez + kumlama (14.85 MPa), Multilink S frez + kumlama (13.80 MPa), Panavia F frez + lazer (9.59 MPa), Panavia $\mathrm{F}$ frez + asit (9.52MPa), Panavia F frez ( 9.46 $\mathrm{MPa})$, Multilink S frez + asit (7.58 MPa), Multilink S frez + lazer (7.51 MPa), Multilink S frez (7.50 MPa), Panavia F yüzey işlemi yapılmayan (3.69 MPa) grup izlemiștir. En düşük bağlanma dayanımı değerleri ise Multilink S yüzey işlemi yapılmayan grupta $(2.44$ MPa) tespit edilmiştir (Tablo 1).

Tablo 1: Deney gruplarına ait bağlanma direnci değerlerinin ortalama, standart sapma ve Duncan testi sonuçları $(N=10),(X=M P a)$

\begin{tabular}{|c|c|c|c|}
\hline Rezin Siman & Yüzey İşlemleri & Ortalama* & Standart Sapma \\
\hline \multirow{6}{*}{ Multilink S } & Yüzey işlemi yapılmayan & $2.44 \mathrm{~g}$ & 0.682 \\
\hline & Frez & $7.50 \mathrm{e}$ & 0.832 \\
\hline & Frez+ Kumlama & $13.80 \mathrm{c}$ & 0.649 \\
\hline & Frez+ Co-Jet & $15.22 \mathrm{~b}$ & 0.694 \\
\hline & Frez+ Asit & $7.58 \mathrm{e}$ & 0.805 \\
\hline & Frez+ Lazer & $7.51^{\mathrm{e}}$ & 0.633 \\
\hline \multirow{6}{*}{ Panavia F } & Yüzey işlemi yapılmayan & $3.69 \mathrm{f}$ & 0.783 \\
\hline & Frez & $9.52 \mathrm{~d}$ & 0.702 \\
\hline & Frez+ Kumlama & $14.85 \mathrm{~b}$ & 0.558 \\
\hline & Frez+ Co-Jet & $15.96 \mathrm{a}$ & 0.553 \\
\hline & Frez+ Asit & $9.46 \mathrm{~d}$ & 0.806 \\
\hline & Frez+ Lazer & $9.59 \mathrm{~d}$ & 0.758 \\
\hline
\end{tabular}

* Aynı harfleri taşıyan gruplar arasındaki fark önemsizken, farklı harfleri taşıyan gruplar arasındaki fark istatistiksel olarak önemlidir (p<.05). 
Yapılan çoklu karşılaştırma (Duncan) testi sonucunda;

- $\quad$ Multilink S frez + Co-Jet grubu ile Panavia F frez + kumlama grubunun,

- Panavia F frez + lazer, Panavia F frez + asit ve Panavia F frez gruplarının,

- Multilink S frez + asit, Multilink S frez + lazer ve Multilink S frez gruplarının birbirlerinden farklı olmadığı diğer grupların ise birbirlerinden ve bu gruplardan farklı olduğu istatistiksel olarak saptanmıştır (Şekil 3).

Şekil 3: Farklı yüzey işlemleri uygulanan örneklerin rezin simanlar ile bağlanma dayanımları

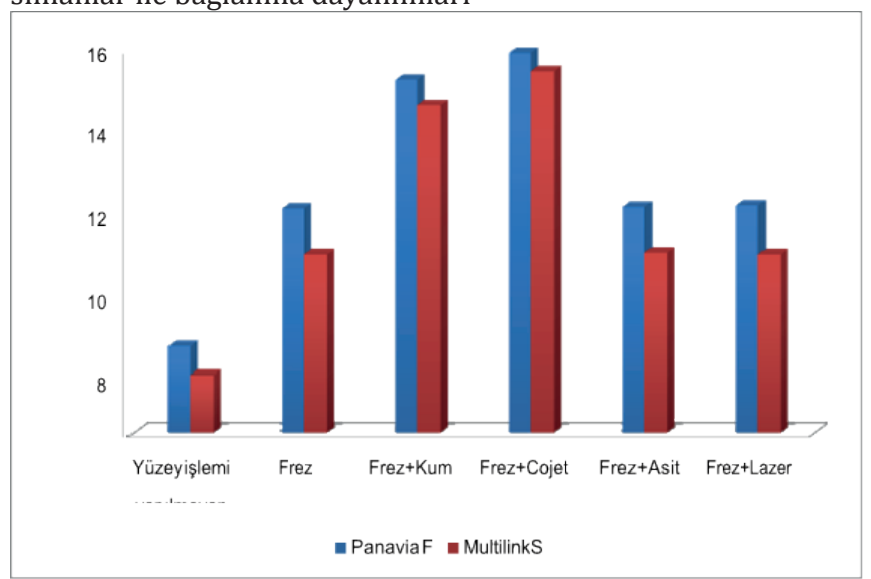

\section{SEM Bulgulari:}

Yüzey pürüzlendirme işlemlerinin titanyum örneklerin yüzeylerinde oluşturduğu etkileri incelemeye yönelik yapılan SEM analizleri sonucunda;

- hiçbir pürüzlendirme yapılmayan grupta örneklerin yüzeyinin düzgün olduğu (Șekil 4),

- elmas frez ile pürüzlendirilen örneklerin yüzeylerinin, yüzey işlemi yapılmayan gruptaki örneklerin yüzeyinden daha pürüzlü bir yüzey (Șekil 5) gösterdiği,

- elmas frez ile pürüzlendirildikten sonra Co-Jet uygulanan örneklerin yüzeylerinin yalnızca frez ile pürüzlendirilen örneklerin pürüzlülüğün bariz bir şekilde arttığı (Şekil 6),

- elmas frez ile pürüzlendirmeye ek olarak kumlama yapılan örneklerin elmas frez + Co-Jet uygulanan gruba göre daha pürüzlü yüzey ve yer yer çukurlar gösterdiği (Şekil 7),

- elmas frez ile pürüzlendirildikten sonra lazer uygulanan örneklerin sadece elmas frez ile pürüzlendirilen gruba benzer bir görüntü (Șekil 8) verdiği,

- elmas frez ile pürüzlendirmeye ek olarak asit uygulanan örneklerin sadece elmas frez ile pürüzlendirilen ve elmas frez ile pürüzlendirmeye ek olarak lazer uygulanan örneklere benzer görüntüler (Şekil 9) gösterdiği saptanmıștır.
Şekil 4: Yüzey ișlemi yapılmayan örnek (×500)

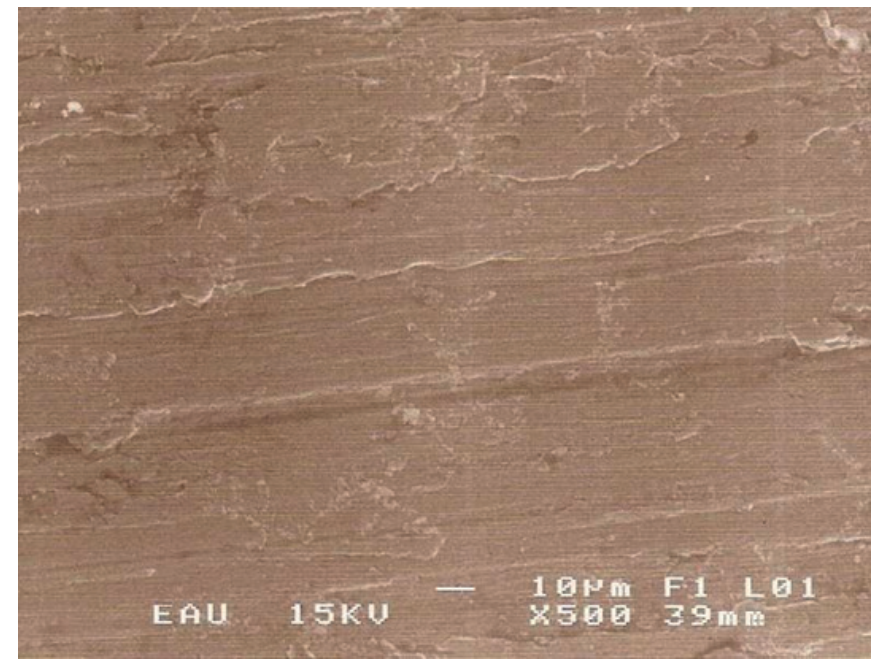

Şekil 5: Elmas frez ile pürüzlendirilen örnek $(\times 500)$

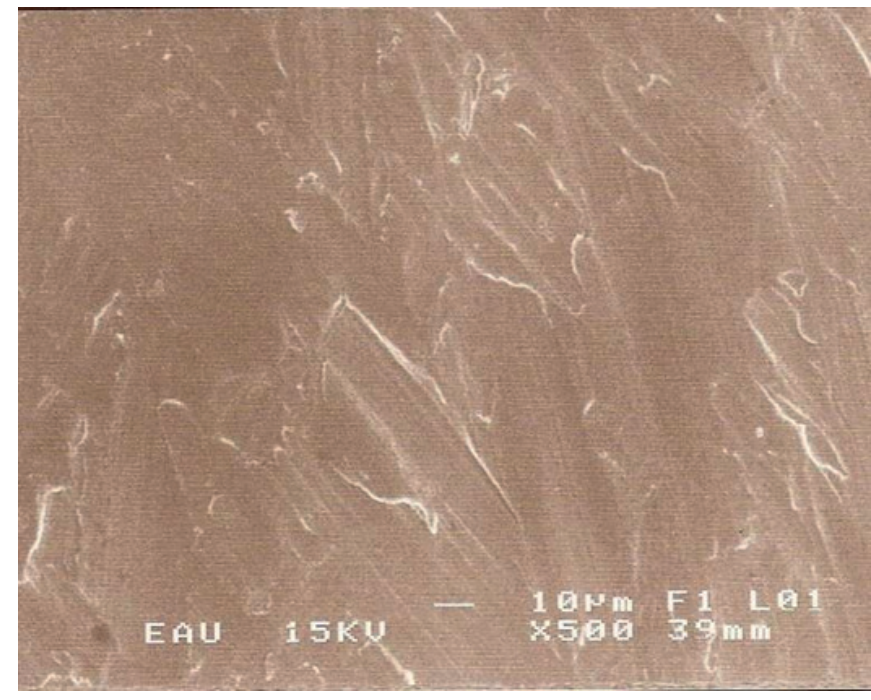

Şekil 6: Elmas frez ile pürüzlendirilen Co-Jet uygulanan örnek $(\times 500)$

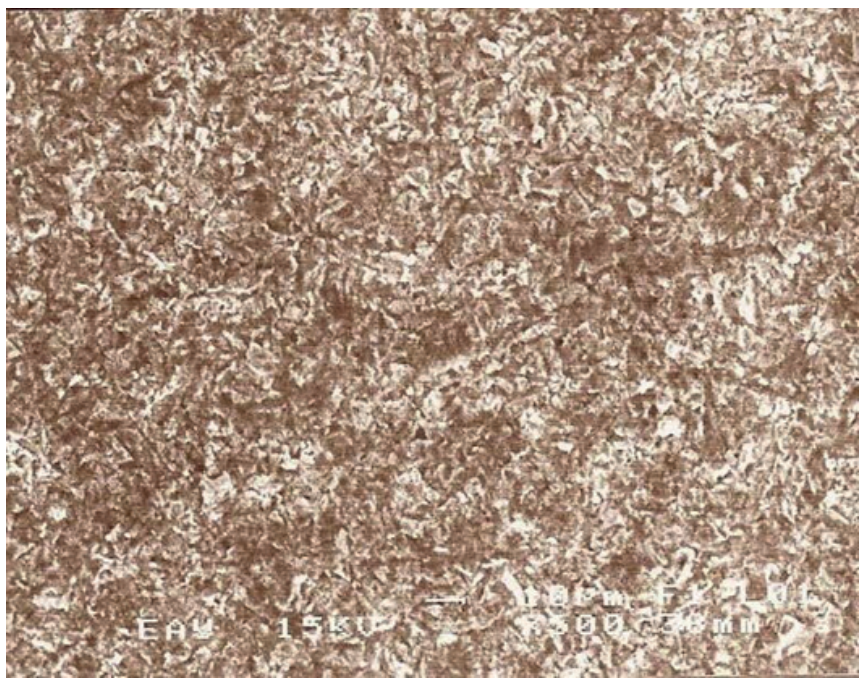


Şekil 7: Elmas frez ile pürüzlendirilen kumlama yapılan örnek $(\times 500)$

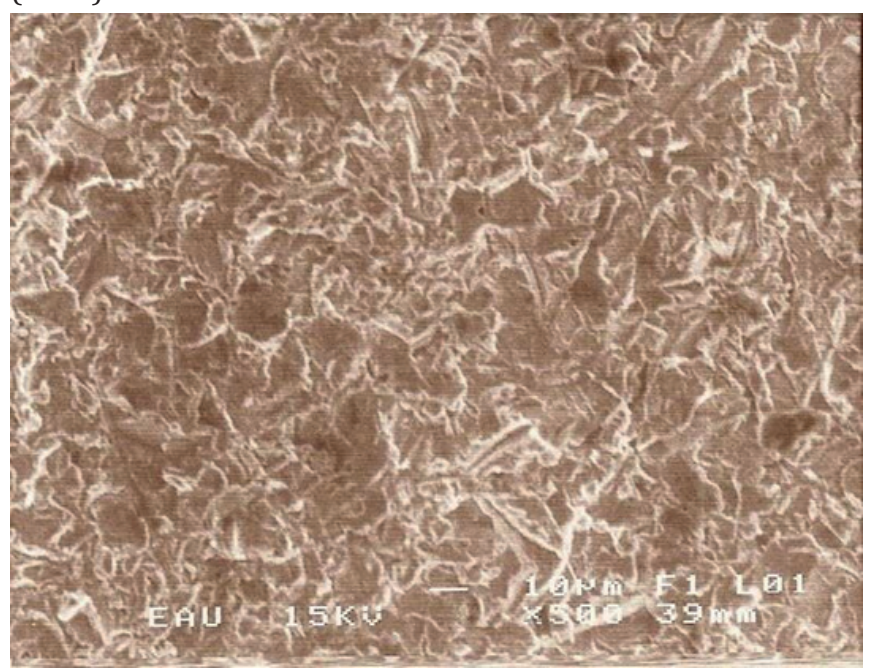

Şekil 8: Elmas frez ile pürüzlendirilen lazer uygulanan örnek $(\times 500)$

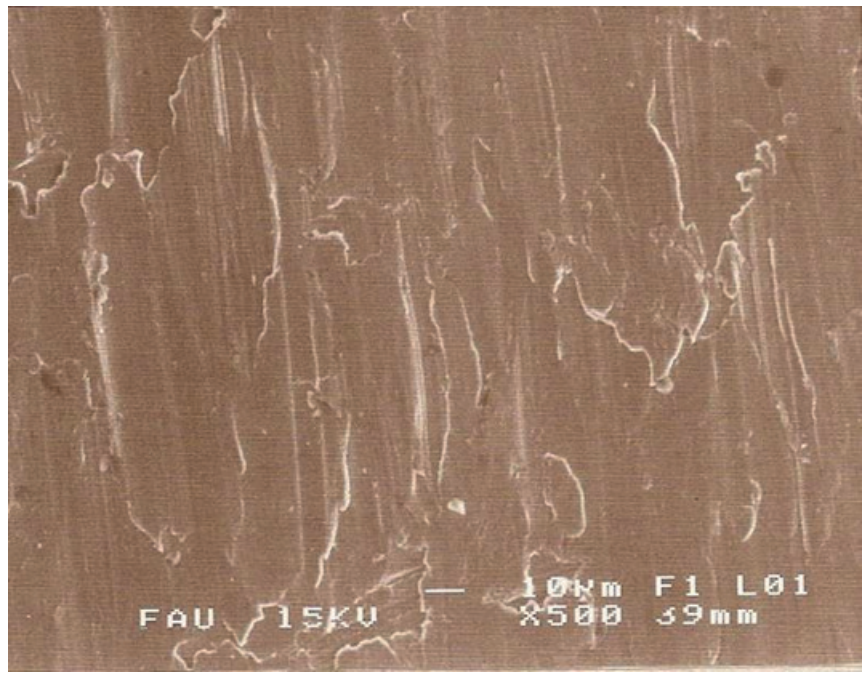

Şekil 9: Elmas frez ile pürüzlendirilen asit uygulanan örnek $(\times 500)$

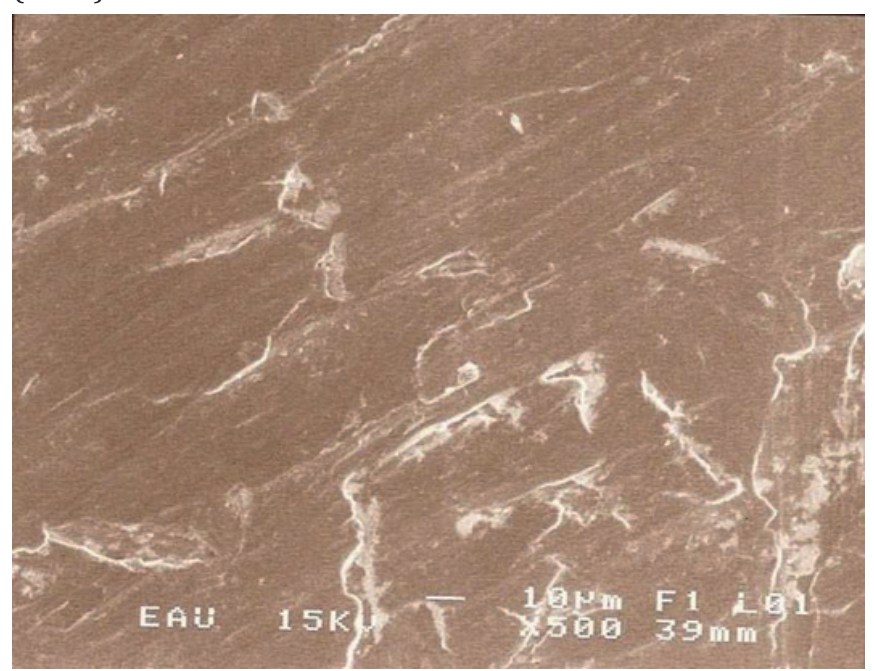

\section{TARTIŞMA}

Dental implant abutmentleri arasında en popüler seçeneğin siman bağlantılı implant abutmentleri ${ }^{14,15}$ olması nedeniyle bu çalışmada, abutment ile siman arasında oluşan bağlantıya yüzey işlemlerinin etkisi incelenmiș, yüzey pürüzlendirme işlemlerinin rezin simanların bağlanma dayanımı değerlerini arttırdığı saptandığından çalışmanın hipotezi kabul edilmiştir.

Yapılan araştırmalar metal ve metal alaşımlarının yüzeyine yapılan çeşitli pürüzlendirme işlemlerinin, bunların üzerine uygulanan restorasyonların veya maddelerin tutuculuğunu arttırdığını göstermiştir. Titanyum ve titanyum alaşımlarında kullanılan yüzey pürüzlendirme yöntemlerinden biri elmas frez ile pürüzlendirme yöntemidir. ${ }^{16,17}$ Bagno ve Di Bello ${ }^{16}$ yapmış oldukları çalışmada saf titanyum ve Ti-6Al-4V örnekleri elmas frez ile pürüzlendirmişlerdir. Uludamar ${ }^{17}$ elmas frez ile pürüzlendirme yöntemini zirkonyum örnekler üzerinde uygulamış, frezle pürüzlendirme işleminin bağlanma dayanımını artırdığını saptamıștır. İmplant destekli protez yapımı sırasında ölçü ile birlikte laboratuvara gönderilen abutmentlerin laboratuvarda frez ile şekillendirilmesi nedeniyle, bu çalışmada yüzey işlemi yapılmayan grup haricindeki tüm gruplarda elmas frez ile pürüzlendirme işlemi yapılmıştır. Elde edilen veriler elmas frez ile pürüzlendirme yapılan grubun bağlanma dayanımı ile yüzey işlemi yapılmayan grubun bağlanma dayanımı arasında istatistiksel olarak anlamlı fark olduğunu göstermiștir. Bu bulgu frezle pürüzlendirme işleminin abutment-rezin siman bağlanma dayanımını artırdığı sonucuna götürmüștür.

Yapılan pek çok çalışmada, titanyum örnekler, rezin siman ile yapıştırılmadan önce $50 \mu \mathrm{m}^{\prime} l u k \mathrm{Al}_{2} \mathrm{O}_{3}$ ile kumlanmıştır. Çalışmaların tamamında kumlama işlemininin, örneklerin bağlanma dayanımını istatistiksel olarak önemli şekilde artırdığı ifade edilmiştir. ${ }^{18-22} \mathrm{Bu}$ çalışmada 20 adet titanyum alaşım örneğe, elmas frez ile pürüzlendirme işlemi yapıldıktan sonra, rezin siman uygulanmadan önce, yukarıdaki çalışmalara benzer şekilde, $50 \mu \mathrm{m}^{\prime}$ luk $\mathrm{Al}_{2} \mathrm{O}_{3}$ ile kumlama işlemi uygulanmış ve bağlanma dayanımı testleri yapıldıktan sonra istatistiksel değerlendirme yapılmıştır. Yüzeyleri frez ile pürüzlendirildikten sonra kumlama yapilan örneklerin oluşturduğu grup ile sadece frez ile pürüzlendirilen grup ve diğer gruplar arasında istatistiksel olarak önemli fark tespit edilmiştir. Bu sonucun, elmas frez ile yüzey pürüzlendirme işlemi yapılarak makro mekanik bir tutuculuk elde edilmesine ilaveten kumlama işlemi ile Ti- 6Al$4 \mathrm{~V}$ yüzeylerinin temizlenmesine ve böylece mikro tutucu yüzey oluşmasına buna bağlı olarak da yüzey alanının ve ıslanabilirliğinin artmasına bağlı olduğu düşünülmektedir.

Co-Jet sistemi klinikte kullanılabilen tribokimyasal 
silika kaplama yöntemi olup, kaplayıcı-așındırıcı kum ve silandan olușmaktadır. Bu yöntemde, silisilik asit içeren $30 \mu \mathrm{m}^{\prime}$ lik $\mathrm{Al}_{2} \mathrm{O}_{3}$ kum partikülleri $90^{\circ}$ lik açıyla, 2.5 atmosfer basinçla, 15 saniye boyunca püskürtüldüğünde, yüzey küçük silika partikülleri ile kaplanmakta, böylece hem yüzey alanı arttığı için mikromekanik tutuculuk elde edilmekte hem de silan uygulaması ile kimyasal tutuculuk sağlanmaktadır. ${ }^{23}$ $\mathrm{Bu}$ çalıșmada da Co-Jet uygulanan titanyum alașım örnekler en yüksek bağlanma dayanımı değerlerini vermiștir. Bunun nedeninin, hem yüzey alanı arttığı için mikromekanik tutuculuk elde edilmesi hem de silan uygulaması ile kimyasal tutuculuk sağlanması olduğu düşünülmektedir.

Tsuchimoto ve ark. ${ }^{11}$ titanyum örneklere Panavia F simanın bağlanma dayanımını ölçmeyi amaçlamışlar, simanı uygulamadan önce titanyum yüzeylerini $\mathrm{HCl}$ asit ve \%37' lik fosforik asit ile asitlemişlerdir. Çalışmaları sonucunda asitlenmiş titanyum örneklerin bağlanma değeri ile yüzey işlemi yapılmayan grubun bağlanma değeri arasında önemli bir fark olmadığını ifade etmişlerdir.

Bu çalışmada, elmas frez ile pürüzlendirildikten sonra \% 37' lik fosforik asit uygulanan gruba ait bağlantı dayanımı değerleri ile sadece elmas frez ile pürüzlendirilen gruba ait bağlantı değerleri arasında istatistiksel olarak önemli fark olmadı $\breve{g}$, diğer gruplar ile bu gruplar arasında ise istatistiksel olarak önemli fark olduğu görülmüștür. Bu sonuç, Tsuchimoto ve ark. ${ }^{11}$ sonuçlarıyla uyum göstermemektedir. Yapılan çalışmada fosforik asit uygulanan gruptaki bağlantı değerlerinin herhangi bir işlem yapılmayan gruptan fazla olmasına, asit uygulanmadan önce frez ile pürüzlendirme işlemi yapılması sebep olmuş olabilir.

Titanyum implantlar ve titanyum abutmentler üzerinde Er:YAG lazer ile pürüzlendirme yapılan çalışmalar bulunmaktadır. ${ }^{10} \mathrm{Bu}$ çalışmalarda Er:YAG lazerin titanyum abutmentin rezin simana bağlanmasına olan etkisi değil, genellikle lazerin implantın biyouyumluluğuna ve osteointegrasyonuna olan etkisi araștırılmaktadır. Lazerlerin, titanyum ve titanyum alaşım abutmentlerin rezin simana bağlanmasına etkisinin incelendiği araştırma sayısı oldukça azdır. ${ }^{24,25}$

Çalışmamızda sadece frez ile pürüzlendirilen grubun bağlanma değerleri ile frez ile pürüzlendirildikten sonra Er:YAG lazer uygulanan grubun bağlanma değerleri arasında istatistiksel olarak önemli fark olmamasına karşın, herhangi bir yüzey işlemi yapılmayan grup ile arasında istatistiksel olarak önemli fark saptanmıştır.

SEM görüntülerinde; en girintili çıkıntılı yüzey yapısının elmas frezle pürüzlendirme yapıldıktan sonra Co-Jet uygulanan yüzeylerde olduğu görülmüş, bunu elmas frezle pürüzlendirme yapıldıktan sonra kumlama yapılan grup takip etmiştir. Elmas frezle pürüzlendirme yapıldıktan sonra Er:YAG lazer ile pürüzlendirilen ve elmas frezle pürüzlendirme yapıldıktan sonra \% 37' lik fosforik asit uygulanan yüzeylerin SEM görüntüleri, elmas frezle pürüzlendirme yapıldıktan sonra hiç bir işlem yapılmayan grubun görüntülerine benzerlik göstermiştir. $\mathrm{Bu}$ benzerlikten hareket edilerek, lazer ve asit ile yapılan pürüzlendirmenin titanyum örneklerin yüzey yapısını değiştirmede etkili olmadığı kanaatine varılmıştır. Herhangi bir yüzey işlemi yapılmayan gruptaki örneklerin ise nispeten pürüzsüz bir yüzeye sahip olduğu görülmüştür.

\section{SONUÇ}

Uygulanan yüzey pürüzlendirme yöntemleri arasında elmas frez ile pürüzlendirme yapıldıktan sonra Co-Jet uygulanan grubun en yüksek değerleri verdiği, bunu elmas frez ile pürüzlendirildikten sonra $\mathrm{Al}_{2} \mathrm{O}_{3}$ ile kumlanan grubun takip ettiği, en düşük bağlanma dayanımını ise yüzey işlemi yapılmayan grubun verdiği saptanmıștır.

Kullanılan rezin simanlardan Alloy Primer ile birlikte kullanılan Panavia F, farklı yüzey pürüzlendirme yöntemlerinin uygulandığı tüm gruplarda Multilink Sprint'e göre daha fazla bağlanma dayanımı göstermiştir.

SEM görüntülerinde, elmas frezle pürüzlendirme yapıldıktan sonra Co-Jet uygulaması ve $50 \mu \mathrm{m}$ partikül büyüklüğünde $\mathrm{Al}_{2} \mathrm{O}_{3}$ ile kumlama, bağlantı yüzeyini en fazla artıran yüzey hazırlık işlemleri olarak bulunmuştur. En girintili çıkıntılı yüzey yapısı elmas frezle pürüzlendirme yapıldıktan sonra Co-Jet uygulanan yüzeylerde görülmüss, bunu elmas frezle pürüzlendirme yapıldıktan sonra kumlama yapılan grup takip etmiştir.

\section{KAYNAKLAR}

1. Davarpanah M, Martinez H. Clinical manual of implant dentistry. London: Qiuintessence; 2004. p.12358.

2. Misch CE, Misch CM. Generic terminology for endosseous implant prosthodontics. J Prosthet Dent. 1992;68: 809-12.

3. Montenegro AC, Machado AN, Depes Gouvea CV. Tensile strength of cementing agents on the CeraOne system of dental prosthesis on implants. Implant Dent. 2008; 17:451-60.

4. Squier RS, Agar JR, Duncan JP, Taylor TD. Retentiveness of dental cements used with metallic implant components. Int J Oral Maxillofac Implants. 2001;16:793-8.

5. Soto-Peñaloza D, Zaragozí-Alonso R, PeñarrochaDiago M, Peñarrocha-Diago M. The all-on-four treatment concept: Systematic review. J Clin Exp Dent 2017;9(3):474-88. Wataha JC. Principles of biocompatibility for dental practitioners. J Prosthet Dent. 
2001;86:203-9.

6. Squier RS, Agar JR, Duncan JP, Taylor TD. Retentiveness of dental cements used with metallic implant components. Int J Oral Maxillofac Implants. 2001;6: 793-8.

7. Taira Y, Yoshida K, Matsumura H, Atsuta M. Phosphate and thiophosphate primers for bonding prosthodontic luting materials to titanium. J Prosthet Dent. 1998;79:384-8.

8. Dudley JE, Richards LC, Abbott JR. Retention of cast crown copings cemented to implant abutments. Aust Dent J. 2008;53:332-9.

9. Matsuyama T, Aoki A, Oda S, Yoneyama T, Ishikawa I. Effects of the Er:YAG laser irradiation on titanium implant materials and contaminated implant abutment surfaces. J Clin Laser Med Surg. 2003;21:7-17.

10. Misch CE. Dental implant protezler. İstanbul: Nobel Tip Kitabevleri; 2009:43-52.

11. Tsuchimoto Y, Yoshida Y, Takeuchi M, Mine A, Yatani $\mathrm{H}$, Tagawa $\mathrm{Y}$, et al. Effect of surface pre-treatment on durability of resin-based cements bonded to titanium. Dent Mater. 2006;22:545-52.

12. Flood AM. Resin bonded prostheses: clinical guidelines. Aust Dent J. 1989;34:209-18.

13. Watanabe I, Aoki T, Okabe T. Grindability of cast Ti-6Al-4V alloyed with copper. J Prosthodont. 2009;18:152-5.

14. Schmalz G. Modern concepts in biocompatibility testing of dental restorative materials. Trans Acad Dent Mater. 1996; 9:170-9.

15. Montenegro AC, Machado AN, Depes Gouvea CV. Tensile strength of cementing agents on the CeraOne system of dental prosthesis on implants. Implant Dent. 2008;17:451-60.

16. Bagno A, Di Bello C. Surface treatments and rough- ness properties of Ti-based biomaterials. J Mater Sci Mater Med. 2004;15:935-49.

17. Uludamar A. Zirkonyum oksit seramik restorasyonlarda farklı yüzey hazırlıklarının kompozit yapıstırma simanının bağlanmasına etkisinin incelenmesi Selçuk Üniversitesi, Doktora tezi, Konya; 2007.

18. Imbery TA, Evans DB, Koeppen RG. A new method of attaching cast gold occlusal surfaces to acrylic resin denture teeth. Quintessence Int. 1993;24:29-33.

19. Taira Y, Matsumura H, Yoshida K, Tanaka T, Atsuta M. Influence of surface oxidation of titanium on adhesion. J Dent. 1998;26:69-73.

20. Matsumura H, Kamada K, Tanoue N, Atsuta M. Effect of thione primers on bonding of noble metal alloys with an adhesive resin. J Dent. 2000;28:287-93.

21. Kim Y, Yamashita J, Shotwell JL, Chong KH, Wang HL. The comparison of provisional luting agents and abutment surface roughness on the retention of provisional implant-supported crowns. J Prosthet Dent. 2006; 95: 450-5.

22. Kahvecioğlu S. Bir rezin simanın dört farklı metal alasıma bağlanma dayanımına metal primerlerin etkisi Selçuk Üniversitesi, Doktora tezi, Konya; 2006.

23. Rubin R. Zirkonya altyapılı restorasyonların dișe bağlantı özelliklerinin incelenmesi İstanbul Üniversitesi, Doktora Tezi, İstanbul; 2007.

24. Quaranta A, Maida C, Scrascia A, Campus G, Quaranta M. Er:Yag Laser application on titanium implant surfaces contaminated by Porphyromonas gingivalis: a histomorphometric evaluation. Minerva Stomatol. 2009;58:317-30.

25. Korkmaz FM, Ates SM, Caglar IS, Baygin O, Duymus ZY. Effect of different surface treatments on the repair bond strength of resin composites with titanium. J Adhesion Science and Technology. 2019; 33( 21): 23852403. 